\title{
Allotropes of Carbon Nanotubes with MWCNTs
}

\section{Kevin James Hughes*}

Professor, Department of Engineering, Simpson College, North C Street Indianola, lowa, USA

\begin{abstract}
Carbon nanotubes (CNTs) are allotropes of carbon with a nanostructure which will have a length-to-diameter quantitative relation bigger than $1,000,000$. Techniques are developed to supply nanotubes in sizeable quantities, together with arc discharge, optical device ablation, and chemical vapor deposition. Developments within the past few years have illustrated the possibly revolutionizing impact of nanomaterials, particularly in medical specialty imaging, drug delivery, biosensing, and also the style of practical nanocomposites. Strategies to effectively interface proteins with nanomaterials for realizing these applications still evolve.
\end{abstract}

The high surface-to-volume quantitative relation offered by nanoparticles resulted within the concentration of the immobilized entity being significantly beyond that afforded by different materials. There has conjointly been AN increasing interest in understanding the influence of nanomaterials on the structure and performance of proteins. varied immobilization strategies are developed, and particularly, specific attachment of enzymes on carbon nanotubes has been a crucial focus of attention. With the growing attention paid to cascade catalyst reaction, it's attainable that multienzyme coimmobilization would be one among ensuing goals within the future. During this paper, we tend to concentrate on advances in methodology for catalyst immobilization on carbon nanotubes.

Keywords: Carbon nanotubes; Allotopes; Nanomaterials; Immobilization

\section{Introduction}

Diamond and plumbago are thought of as 2 natural crystalline styles of pure carbon. In diamond, carbon atoms exhibit pairing, within which four bonds are directed towards the corners of a daily tetrahedron. The ensuing three-dimensional network (diamond) is extraordinarily rigid, that is one reason for its hardness. In plumbago, pairing happens, within which every atom is connected equally to a few carbons $\left(120^{\circ}\right)$ within the plane, and a weak bond is gift within the axis. The set forms the hexangulare (honeycomb) lattice typical of a sheet of plumbago [1]. A brand new sort of carbon, Buckminster C, was discovered in 1985 by a team headed by Korto and coworkers [2]. Besides diamond, graphite, and C, quasi-one-dimensional carbon nanotube is ANother sort of carbon initial reportable by Ijima in 1991 once he discovered multiwalled carbon nanotubes (MWCNTs) in carbon soot created by an arc-discharge methodology [3]. Carbon nanotubes (CNTs) are allotropes of carbon. CNTs are hollow in form, fabricated from plumbago. The tubes contained a minimum of 2 layers, typically more, and ranged in outer diameter from concerning $3 \mathrm{~nm}$ to $30 \mathrm{~nm}$. Concerning 2 years later, he created the observation of singlewalled carbon nanotubes (SWCNTs) [4]. At concerning constant time, Dresselhaus et al., synthesized single-walled carbon nanotubes by constant route of manufacturing MWCNTs however adding some transition metal particles to the carbon electrodes [5].

\section{Structure and Morphology}

Comprised entirely of carbon, the structure of pure SWCNT will be envisioned as folded hollow shell of graphene sheet that is formed of aromatic hydrocarbon sort hexangulare rings of carbon atoms. Graphene sheets are seamless cylinders derived from a honeycomb lattice, representing one atomic layer of crystalline plumbago. A MWCNT may be a stack of graphene sheets rolled up into concentrical cylinders. Every carbon nanotube may be a single molecule composed of lots of atoms and also the length of this molecule will be tens of micrometers long with diameters as tiny as $0.7 \mathrm{~nm}$ [6-11].

In addition to the 2 completely different basic structures, there are 3 completely different attainable forms of carbon nanotubes.
These 3 forms of CNTs are armchair carbon nanotubes, zigzag carbon nanotubes, and chiral carbon nanotubes. The distinction in these forms of carbon nanotubes are created looking on however the plumbago is "rolled up" throughout its creation method. the selection of rolling axis relative to the hexangulare network of the printed symbol sheet and also the radius of the closing cylinder permits for various forms of SWCNTs [12-15].

\section{Properties}

The strength of the carbon-carbon bonds offers carbon nanotubes superb mechanical properties. No previous material has displayed the mix of superlative mechanical, thermal, and electronic properties attributed to them. Their densities will be as low as one. $3 \mathrm{~g} / \mathrm{cm}^{3}$ (onesixth of that of untarnished steel) [16]. CNTs Young's moduli (measure of fabric stiffness) are superior to any or all carbon fibres with values bigger than 1TPa that is around $5 \mathrm{x}$ beyond steel [17]. However, their strength is what extremely sets them apart. Carbon nanotubes are the strongest materials ever discovered by humanity.

The highest measured strength or breaking strain for a fullerene was up to $63 \mathrm{GPa}$ that is around fifty times beyond steel [17]. Even the weakest forms of carbon nanotubes have strengths of many touchstones [18]. Besides that, CNTs have smart chemical and environmental stability and high thermal conduction $(\sim 3000 \mathrm{~W} / \mathrm{m} / \mathrm{K}$, corresponding to diamond). These properties, in addition to the lightness of carbon nanotubes, provide them nice potential in applications like region.

*Corresponding author: Kevin James Hughes, Professor, Department of Engineering, Simpson College, North C Street Indianola, lowa, USA, Tel: 1-515-9616251; E-mail: kevin.james@simpson.edu

Received May 19, 2015; Accepted May 20, 2015; Published June 03, 2015

Citation: Hughes KJ (2015) Allotropes of Carbon Nanotubes with MWCNTs. J Nanomed Nanotechnol 6: 302. doi:10.4172/2157-7439.1000302

Copyright: () 2015 Hughes KJ. This is an open-access article distributed under the terms of the Creative Commons Attribution License, which permits unrestricted use, distribution, and reproduction in any medium, provided the original author and source are credited. 
The electronic properties of carbon nanotubes are extraordinary. It's high electrical conduction (comparable to copper). Particularly notable is that the proven fact that nanotubes will be gold or semiconductive.

The rolling action breaks the symmetry of the coplanare system and imposes a definite direction with relevance the hexangulare lattice and also the axial direction. Looking on the connection between this axial direction and also the unit vectors describing the hexangulare lattice, the nanotubes could behave electrically as either a metal or a semiconductor. semiconductive nanotubes have bandgaps that scale reciprocally with diameter, starting from around one. $8 \mathrm{eV}$ for terribly tiny diameter tubes to zero. $18 \mathrm{eV}$ for the widest attainable stable SWCNT [19]. Thus, some nanotubes have conductivities beyond that of copper, whereas others behave a lot of like atomic number 14. there's nice interest within the chance of constructing nanoscale electronic devices from nanotubes. There are many aras of technology wherever carbon nanotubes are already being employed. These embody flat-panel displays, scanning probe microscopes, sensing devices, and electric cell [20].

\section{Carbon Nanotubes Synthesis Techniques}

High-quality carbon nanotube materials square measure desired for each basic and technological applications. top quality refers to the absence of structural and chemical defects over a major length scale (e.g., 1-10 microns) on the tube axes [21]. The quantity of patents and publication on the synthesis of fullerene is increasing apace. But there square measure several challenges remaining that have to be resolved concerning synthesis of CNT. Currently, there square measure four main challenges within the field of carbon nanotube synthesis. (a) Production, that is, the event of inexpensive, large-scale processes for the synthesis of high-quality nanotubes, together with SWCNTs. (b) Selective production, that is, management over the structure and electronic properties of the created nanotubes [22]. (c) Organization, that is, management over the situation and orientation of the created nanotubes on a flat substrate. (d) Mechanism, that is, the event of an intensive understanding of the processes of carbon nanotube growth. The expansion mechanism continues to be a topic of contention, and over one mechanism can be operative throughout the formation of CNTs [23].

A variety of techniques are developed to supply CNTs and MWNTs with totally different structure and morphology in laboratory quantities. There square measure 3 strategies unremarkably wont to synthesize CNT: arc discharge [20,21], optical maser ablation [22], and chemical vapor deposition (CVD) [23-26]. The fundamental components for the formation of nanotubes square measure catalyst, a supply of carbon, and adequate energy. The common feature of those strategies is addition of energy to a carbon supply to supply fragments (groups or single C atoms) which will recombine to get CNT. The energy supply could also be electricity from associate degree arc discharge, heat from a chamber $\left(\sim 900^{\circ} \mathrm{C}\right)$ for $\mathrm{CVD}$, or the high-intensity lightweight from an optical maser (laser ablation) [27].

\section{Arc Discharge and Optical Maser Vaporization}

Arc discharge and optical maser ablation were the primary strategies that allowed synthesis of SWCNTs in comparatively massive (gram) amounts. Each strategy involves the condensation of hot vaporized carbon atoms generated from the evaporation of solid carbon [27]. For the expansion of single-wall tubes, a metal catalyst is required within the arc-discharge system [28]. The expansion of highquality SWCNTs at the $1-10 \mathrm{~g}$ scale was conjointly created employing a laser-ablation (laser oven) methodology [22]. Besides the laser-oven methodology, there square measure reports concerning usage of a typical industrial continuous wave -laser system for production of SWCNTs [29]. Even so, the instrumentality needs and also the great deal of energy consumed by these strategies create them less favorable for carbon nanotube production. With the arc and optical maser strategies, solely powdery samples with nanotubes tangled into bundles may be created. The common feature of arc discharge and optical maser ablation strategies is that they would like for prime quantity of energy to induce the reorganization of carbon atoms into CNTs. The temperature used is even beyond $300^{\circ} \mathrm{C}$, that is useful permanently crystallization of the CNTs, thus, the product square measure invariably created with smart carbon alignment. However, the fundamental needs of those systems, together with vacuum conditions and continuous carbon target replacement, cause difficulties to the large-scale production of CNTs [30].

There square measure 2 main carbon sources for the synthesis of CNTs-using CVD method: fossil-based organic compound and plant primarily based organic compound. Organic compound was long and wide used because the typical carbon supply within the field of CNTs analysis. Gas becomes the foremost desirable carbon supply to several researchers. As a result of its stability at warm temperature against self-decomposition, alkane series chemical \{process, chemical change, chemical action $\}$ decomposition by transition metal catalyst particles is that the dominant process in carbon nanotubes growth. Besides alkane series many different carbon species like alkyne, benzene, xylene, toluene, and then forth, are used as a carbon feedstock to synthesize CNTs. These carbon precursors square measure associated with fossil fuels and in sight of the too little obtainable in close to future and its environmental effects, it's necessary to contemplate developing chemical element materials from the natural resources. Efforts square measure currently directed to the employment of nonpetroleum product. Syntheses of CNTs from natural precursors square measure rare, however, over the past many years natural renewable resources became a lot of engaging thanks to their environmental advantages and lower price. One such considerable effort is to use nondegradable polymers for synthesis of CNTs. There are reports on the employment of natural precursor such as: natural resin , turpentine oil , essential oil, aperient, copra oil , and vegetable oil for synthesis of CNTs. printed knowledge show that, some researchers have used waste cookery vegetable oil because the biocarbon precursor in their studies. Waste vegetable oil, that is way more cost-effective than virgin edible fat, may be a promising various to edible fat for CNT production. Suriani and coworkers reported the employment of waste cookery vegetable oil for the synthesis of vertically aligned carbon nanotubes (VACNT). The result showed that the complicated composition of the waste oil (leaching of fats and different hydrocarbons from the deep-fried objects) failed to have an effect on the synthesis method [29-35].

In recent years, efforts are dedicated to explore the potential biological applications of CNTs, impelled by their attention-grabbing size, shape, and structure, also as engaging optical and electrical properties. First, with all atoms exposed on the surface, SWNTs have ultrahigh area (theoretically $1300 \mathrm{~m}^{2} / \mathrm{g}$ ) that allows economical loading of multiple molecules on the length of the carbon nanotube sidewall. Second, supramoleculare binding of aromatic molecules may be simply achieved by - stacking of these molecules onto the polyaromatic surface of nanotubes. It's been incontestable that biological and bioactive species like proteins, carbohydrates, and nucleic acids may be conjugated with carbon nanotubes [36]. Each noncovalent and valence methods are explored to engineer the interface between biological molecules 
and CNTs with the goal of conserving the purposeful properties of the biomolecules. The biomolecule immobilization on the sidewall of the CNTs, and a lot of curiously within the CNTs has been reported in each procedure and experimental fields. supported these exciting observations and potential applications, the conformational changes of biomolecules in these confined environments tend to be of nice significance principally as a result of these conformational changes littered with the biomolecules-CNT interactions may directly impact their biological functions [37].

However, the atomic details of the interactions at the molecular level, and also the dynamic mechanisms of the biomolecules-CNT systems square measure still difficult thanks to the complexness of the bio macromolecules. The interaction between nanostructured materials and living systems is of basic and sensible interest and can verify the biocompatibility, potential utilities, and applications of novel nanomaterial in biotechnological processes. However, the studies on the CNT-organic nanoparticle hybrid architectures square measure poorly developed relatively. For instance, there aren't enough studies on the influence that the nanomaterial properties (such as composition, morphology, and surface chemistry) ware the structure and performance of conjugated proteins. the foremost necessary parameter all told such studies is that the kind of carbon nanotubes used, that is set by (i) the preparation and producing method followed; (ii) the structural characteristics of the CNTs; (iii) the surface characteristics of the CNTs and also the characteristics of the purposeful teams at the surface of CNTs. Interactions with cells have to be compelled to be performed mistreatment biocompatible CNTs, achieved by either valence or noncovalent surface functionalization to supply soluble CNTs.

\section{The NonCovalent Immobilization}

The noncovalent approach is taken into account to be a splendid technique, as a result of there's less distortion of the conformational structure of the immobilized enzymes. In most cases the interaction between the macromolecule and also the CNTs involves the physically absorbable of the macromolecule onto the CNTs. The surface assimilation of macromolecule onto the CNTs involves each hydrophobic and static interaction [21]. Pristine CNTs being extremely hydrophobic can contribute to hydrophobic interaction through interaction of the facet chains of hydrophobic amino acids of the proteins with the sidewall of CNTS. As for the static interaction, the electrons on the surface of the CNTs can act with the electrons of the aromatic ring of amino acids (e.g., essential amino acid and tryptophan). Except static and hydrophobic interaction, chemical element bonds, and nonspecific surface assimilation may also play a task for protein surface assimilation onto CNTs. The surface assimilation usually involves bathing the CNTs in an exceedingly resolution of the protein and shaking the sample to permit time for the physical surface assimilation onto the surface to occur so remotion away protein that's not absorbable. This method may be distributed by direct physical surface assimilation onto CNTs (direct physical surface assimilation) or adsorption with the help of geare like polymers, surfactants, and linking molecules (specific adsorption). As CNTs have a natural affinity for various proteins, the surface assimilation is spontaneous once proteins are available in contact with CNTs in an exceedingly resolution and follows a pseudosaturation behavior [14].

\section{References}

1. Zhang G, Mann D, Zhang L, Javey A, Li Y, et al. (2005) Ultra-high-yield growth of vertical single-walled carbon nanotubes: Hidden roles of hydrogen and oxygen. Proc Natl Acad Sci USA 102: 16141-16145.
2. Harris PJF (2009) Carbon Nanotube Science-Synthesis, Properties and Application. Cambridge University Press, Cambridge, UK.

3. Zhang M, Li J (2009) Carbon nanotube in different shapes. Materials Today 12: $12-18$.

4. Hennrich F, Chan C, Moore V, Rolandi M, O'Connell M (2003) Carbon Nanotubes Properties and Applications.

5. Elliott JA, Sandler JKW, Windle AH, Young RJ, Shaffer MSP (2004) Collapse of Single-Walled Carbon Nanotubes is Diameter Dependent. Physical Review Letters 92: 1-4.

6. Kroto HW, Heath JR, O'Brien SC, Curl RF, Smalley RE (1985) C60 buckminsterfullerene. Nature 318: 162-163.

7. lijima S (1991) Helical microtubules of graphitic carbon. Nature 354: 56-58.

8. lijima S, Ichihashi T (1993) Single-shell carbon nanotubes of 1-nm diameter Nature 363: 603-605.

9. https://books.google.co.in/books/about/Carbon_Nanotubes. $\mathrm{html}$ ? id=dkvDhZJnafgC\&hl=en

10. Ajayan PM (1999) Nanotubes from Carbon. Chem Rev 99: 1787-1800.

11. Donaldson K, Aitken R, Tran L, Stone V, Duffin R, et al. (2006) Carbon nanotubes: a review of their properties in relation to pulmonary toxicology and workplace safety. Toxicol Sci 92: 5-22.

12. http://en.wikipedia.org/wiki/Carbon_\%28fiber\%29

13. Hirlekar R, Yamagar M, Garse H, Mohit V, Kadam V (2009) Carbon nanotubes and its applications: a review. Asian Journal of Pharmaceutical and Clinical Research 2: 17-27.

14. Meyyappan M, Delzeit L, Cassell A, Hash D (2003) Carbon nanotube growth by PECVD: a review. Plasma Sources Science and Technology 12: 205-216.

15. Dresselhaus MS, Dresselhaus G, Jorio A (2004) Unusual properties and structure of carbon nanotubes. Annual Review of Materials Research 34: 247-278.

16. Lin T, Bajpai V, Ji T, Dai L (2003) Chemistry of carbon nanotubes. Australian Journal of Chemistry 56: 635-651.

17. Saito R, Dresselhaus G, Dresselhaus MS (1998) Physical Properties of Carbon Nanotubes.

18. Terrones M (2003) Science and technology of the twenty-first century: synthesis, properties, and applications of carbon nanotubes. Annual Review of Materials Research 33: 419-501.

19. Zhong GF, Iwasaki T, Honda K, Furukawa Y, Ohdomari I, et al. (2005) Low temperature synthesis of extremely dense and vertically aligned single-walled carbon nanotubes. Japanese Journal of Applied Physics 44: 1558-1561.

20. Yu MF, Files BS, Arepalli S, Ruoff RS (2000) Tensile loading of ropes of single wall carbon nanotubes and their mechanical properties. Phys Rev Lett 84 $5552-5555$.

21. Xie S, Li W, Pan Z, Chang B, Lianfeng S (2000) Mechanical and physical properties on carbon nanotube. Journal of Physics and Chemistry of Solids 61: 1153-1158.

22. Ebbesen TM, Ajayan PM (1992) Large-scale synthesis of carbon nanotubes Nature 358: 220-222

23. Journet C, Maser WK, Bernier P (1997) Large-scale production of single-walled carbon nanotubes by the electric-arc technique. Nature 388: 756-758.

24. Thess A, Lee R, Nikolaev P, Dai H, Petit P, et al. (1996) Crystalline Ropes of Metallic Carbon Nanotubes. Science 273: 483-487.

25. Kong J, Cassell AM, Dai H (1998) Chemical vapor deposition of methane for single-walled carbon nanotubes. Chemical Physics Letters 292: 567-574.

26. Fan S, Chapline MG, Franklin NR, Tombler TW, Cassell AM, et al. (1999) Selforiented regular arrays of carbon nanotubes and their field emission properties. Science 283: 512-514

27. Bower C, Zhou O, Zhu W, Werder DJ, Jin S (2000) Nucleation and growth of carbon nanotubes by microwave plasma chemical vapor deposition. Applied Physics Letters 77: 2767-2769.

28. Su M, Zheng B, Liu J (2000) A scalable CVD method for the synthesis of singlewalled carbon nanotubes with high catalyst productivity. Chemical Physics Letters 322: 321-326. 
29. Dai H (2002) Carbon nanotubes: opportunities and challenges. Surface Science 500: 218-241.

30. Bethune DS, Kiang CH, De Vries MS (1993) Cobalt-catalysed growth of carbon nanotubes with single-atomic-layer walls. Nature 363: 605-607.

31. Muñoz E, Maser WK, Benito AM (2000) Single-walled carbon nanotubes produced by $\mathrm{cw}$ CO2-laser ablation: study of parameters important for their formation. Applied Physics A 70: 145-151.

32. Kumar M, Ando Y (2003) Camphor-a botanical precursor producing garden of carbon nanotubes. Diamond and Related Materials 12: 998-1002.

33. Cassell AM, Raymakers JA, Kong J, Dai H (1999) Large scale CVD synthesis of single-walled carbon nanotubes. Journal of Physical Chemistry B 103: 64846492.
34. Nikolaev P, Bronikowski MJ, Bradley RK (1999) Gas-phase catalytic growth of single-walled carbon nanotubes from carbon monoxide. Chemical Physics Letters 313: 91-97.

35. Kitiyanan B, Alvarez WE, Harwell JH, Resasco DE (2000) Controlled production of single-wall carbon nanotubes by catalytic decomposition of $\mathrm{CO}$ on bimetallic Co-Mo catalysts. Chemical Physics Letters 317: 497-503.

36. Maruyama S, Kojima R, Miyauchi Y, Chiashi S, Kohno M (2002) Lowtemperature synthesis of high-purity single-walled carbon nanotubes from alcohol. Chemical Physics Letters 360: 229-234.

37. Li Y, Mann D, Rolandi M (2004) Preferential growth of semiconducting singlewalled carbon nanotubes by a plasma enhanced CVD method. Nano Letters 4: 317-321. 